\title{
Investigation of Diantipyrylmethane as Corrosion Inhibitor for Mild Steel in Sulfuric Acid Solution
}

\author{
Lijuan Gong ${ }^{1, *}$, Kangquan Qiao $^{2,3}$ \\ ${ }^{1}$ College of Bioengineering, Sichuan University of Science \& Engineering, Zigong 643000, P. R. \\ China \\ ${ }^{2}$ Analysis and Testing Center, Sichuan University of Science \& Engineering, Zigong 643000, P. R. \\ China \\ ${ }^{3}$ Material Corrosion and Protection Key Laboratory of Sichuan Province, Zigong 643000, P. R. China \\ *E-mail: g_ljuan@163.com
}

doi: $10.20964 / 2016.12 .20$

Received: 27 July 2016 / Accepted: 11 September 2016 / Published: 10 November 2016

The corrosion inhibition performances of Diantipyrylmethane (DAM) for mild steel in $0.5 \mathrm{M} \mathrm{H}_{2} \mathrm{SO}_{4}$ were investigated using weight loss, electrochemical impedance spectroscopy (EIS), potentiodynamic polarization, scanning electron microscope (SEM) and quantum chemical calculation. The obtained results reveal that DAM acts as a mixed-type inhibitor with a predominantly anodic reaction, and the inhibition efficiency increases with increasing inhibitor concentration whereas decreases with increasing temperature. The adsorption of DAM on steel surface is found to obey Langmuir isotherm, and the adsorption mechanism is mixed physical and chemical adsorption. The results of quantum chemical calculation demonstrate that pyrazolone rings within molecular structure of DAM play a dominant role in corrosion inhibition of mild steel.

Keywords: Diantipyrylmethane, Mild steel, Acid Corrosion

\section{FULL TEXT}

(C) 2016 The Authors. Published by ESG (www.electrochemsci.org). This article is an open access article distributed under the terms and conditions of the Creative Commons Attribution license (http://creativecommons.org/licenses/by/4.0/). 